\title{
SLC39A8 deficiency: biochemical correction and major clinical improvement by manganese therapy
}

\author{
Julien H. Park ${ }^{1}$, Max Hogrebe ${ }^{1}$, Manfred Fobker, PhD², Renate Brackmann, MD³, Barbara Fiedler, MD¹, \\ Janine Reunert, $\mathrm{PhD}^{1}$, Stephan Rust, $\mathrm{PhD}^{1}$, Konstantinos Tsiakas, $\mathrm{MD}^{4}$, René Santer, $\mathrm{MD}^{4}$, \\ Marianne Grüneberg ${ }^{1}$ and Thorsten Marquardt, MD $^{1}$
}

\begin{abstract}
Purpose: SLC39A8 deficiency is a severe inborn error of metabolism that is caused by impaired function of manganese metabolism in humans. Mutations in SLC39A8 lead to impaired function of the manganese transporter ZIP8 and thus manganese deficiency. Due to the important role of $\mathrm{Mn}^{2+}$ as a cofactor for a variety of enzymes, the resulting phenotype is complex and severe. The manganesedependence of $\beta$-1,4-galactosyltransferases leads to secondary hypoglycosylation, making SLC39A8 deficiency both a disorder of trace element metabolism and a congenital disorder of glycosylation. Some hypoglycosylation disorders have previously been treated with galactose administration. The development of an effective treatment of the disorder by high-dose manganese substitution aims at correcting biochemical, and hopefully, clinical abnormalities.
\end{abstract}

Methods: Two SCL39A8 deficient patients were treated with 15 and $20 \mathrm{mg} \mathrm{MnSO}_{4} / \mathrm{kg}$ bodyweight per day. Glycosylation and blood manganese were monitored closely. In addition, magnetic resonance imaging was performed to detect potential toxic effects of manganese.

Results: All measured enzyme dysfunctions resolved completely and considerable clinical improvement regarding motor abilities, hearing, and other neurological manifestations was observed.

Conclusion: High-dose manganese substitution was effective in two patients with SLC39A8 deficiency. Close therapy monitoring by glycosylation assays and blood manganese measurements is necessary to prevent manganese toxicity.

Gent Med advance online publication 27 July 2017

Key Words: congenital disorder of glycosylation; manganese; Parkinsonism; therapy

\section{INTRODUCTION}

SLC39A8 deficiency, or SLC39A8-CDG (CDG-IIn; OMIM 616721), is a recently identified disorder that impairs human manganese metabolism by disrupting the function of a major manganese transport protein, ZIP8. ${ }^{1,2}$ Manganese is the twelfth most abundant element found on $\mathrm{Earth}^{3}$ and plays a major biological role as an important cofactor in a variety of enzymes. ${ }^{4,5}$ Due to the multiple ways of manganese involvement in human metabolism, individuals suffering from SLC39A8 deficiency show diverse phenotypes with affection of several organ systems. Glycosylation abnormalities define it as a type II congenital disorder of glycosylation (CDG). ${ }^{1}$ Hypoglycosylation in SLC39A8 deficiency is caused by hindered galactosylation of nascent glycan chains due to manganese dependence of $\beta$-1,4-galactosyltransferases (EC 2.4.1.38). ${ }^{6,7}$ Defective galactosylation accounts for phenotypical similarities to SLC35A2-CDG, in which the transport of UDP-galactose into the Golgi apparatus is affected. ${ }^{8,9}$

Major clinical symptoms are cranial synostoses with lacunar skull, cerebral and cerebellar atrophy, severe psycho- motor disability, seizures, and vision and hearing impairment.

The exact pathomechanism underlying these symptoms is poorly understood. While some can be explained by manganese dependence of additional metalloenzymes such as superoxide dismutase 2 (EC 1.15.1.1), pyruvate carboxylase (EC 6.4.1.1), and glutamine synthase (EC 6.3.1.2), ${ }^{5}$ others might be secondary effects of hypoglycosylation.

Galactose supplementation had a favorable effect on both glycosylation and clinical presentation in a severely affected child with SLC39A8 deficiency. ${ }^{1}$ Of course, this therapeutic approach can only treat those symptoms attributable to hypogalactosylation. Galactose supplementation corrects the malfunction of $\beta$-1,4-galactosyltransferase but not of the other manganese-dependent metalloenzymes. We therefore introduced high amounts of manganese(II)-sulfate monohydrate to the patients' diet to reach sufficient manganese levels to correct all biochemical abnormalities, thereby establishing a causative therapy for SLC39A8 deficiency. We report on biochemical as well as clinical effects following more than 1 year of manganese (II)-sulfate monohydrate supplementation in two patients.

\footnotetext{
${ }^{1}$ Klinik und Poliklinik für Kinder- und Jugendmedizin-Allgemeine Pädiatrie, Universitätsklinikum Münster, Münster, Germany; ${ }^{2}$ Centrum für Laboratoriumsmedizin, Universitätsklinikum Münster, Münster, Germany; ${ }^{3}$ Sozialpädiatrisches Zentrum, Johannes-Wessling-Klinikum, Minden, Germany; ${ }^{4}$ Klinik für Kinder- und Jugendmedizin, Universitätsklinikum Hamburg-Eppendorf, Hamburg, Germany. Correspondence: Thorsten Marquardt (thorsten.marquardt@ukmuenster.de) 


\section{MATERIALS AND METHODS}

All procedures were in accordance with the ethical standards of the responsible institutional committee on human experimentation and with the Helsinki Declaration of 1975, as revised in 2000. The study performed was an individual experimental therapy and consent from the local ethics committee (Ethik-Kommission der Ärztekammer WestfalenLippe und der Westfälischen Wilhelms-Universität) was obtained. Informed consent was obtained from the subjects' legal guardians.

\section{Manganese(II)-sulfate monohydrate $\left(\mathrm{MnSO}_{4} \cdot \mathrm{H}_{2} \mathrm{O}\right)$}

Manganese(II)-sulfate monohydrate (Carl Roth, Karlsruhe, Germany) was chosen due to its high solubility as well as the favorable oxidation state of manganese. ${ }^{10}$ The preparation complies with the standards of the European Pharmacopoeia.

\section{Subject A}

An extended report on the subject's phenotype and initial presentation can be found elsewhere. ${ }^{1}$ In short, she presented with severe skeletal abnormalities consisting of cranial synostoses and lacunar skull, cerebral atrophy, infantile spasms with hypsarrhythmia, severe psychomotor disability, and muscular hypotonia. Next-generation sequencing revealed two mutations in SLC39A8 (c. [112G $>$ C]; $[1019 \mathrm{~T}>\mathrm{A}])$ resulting in two amino acid exchanges at highly conserved sites in the gene product (p. [Gly38Arg]; [p.Ile340Asn]) (ClinVar: SCV000256230).

At the beginning of $\mathrm{MnSO}_{4} \cdot \mathrm{H}_{2} \mathrm{O}$ substitution, the girl was 8 months old.

\section{Subject B}

Subject B is the second individual affected by SLC39A8 deficiency who was identified in the Münster cohort of unsolved CDG patients. ${ }^{1}$ She was found to carry three different mutations in SLC39A8 c.[97G > A;1004G >C]; [610G $>$ T] (ClinVar: SCV000256231). Her phenotype is milder and resembles that of the patients described by Boycott et al. $^{2}$ Global psychomotor disability as well as seizures started in the first year of life. She has cerebellar atrophy as well as strabismus and scoliosis. The young woman was 19 years old when manganese supplementation was first introduced.

\section{Therapy protocol}

Subject A was given an initial dose of $10 \mathrm{mg} \mathrm{MnSO}_{4} \cdot \mathrm{H}_{2} \mathrm{O} /$ day dissolved in water, which was added to her usual diet and was gradually increased. Initially, she was fed via a J-tube over the course of 22 hours. At the same time, the subject's galactose substitution (dosage: $3.75 \mathrm{~g} / \mathrm{kg}$ bodyweight) was tapered and eventually stopped altogether. The manganese dosage was increased when galactose tapering led to impaired glycosylation, as depicted in Figure 1, thus determining the minimal manganese dose necessary for complete biochemical correction in the absence of galactose. Due to major improvements of swallowing and her general condition, J-tube feeding was discontinued during the course of the treatment. Afterwards, the daily quantity of $\mathrm{MnSO}_{4} \cdot \mathrm{H}_{2} \mathrm{O}$ was given orally in five equal portions over the course of 24 hours.

Subject B did not receive oral galactose substitution but was given oral manganese supplementation from the beginning. The initial dose of $10 \mathrm{mg} \mathrm{MnSO}_{4} \cdot \mathrm{H}_{2} \mathrm{O}$ /day was given in five equal portions.

Manganese doses were gradually raised over the course of 414 and 449 days respectively until normal levels of transferrin glycosylation were reached. Using this approach, we determined the definitive $\mathrm{MnSO}_{4}$ dose for both patients.

During the treatment, glycosylation was closely monitored by high-performance liquid chromatography using a "CDT in serum" kit (Chromsystems, Gräfelfing, Germany).

In addition, manganese levels in blood as well as in urine and cerebrospinal fluid (CSF) were measured.

Whole-blood and cerebrospinal fluid samples for manganese determination were prepared by producing a 10 -fold diluted with a $1 \% \mathrm{HNO}_{3}$ solution (urine 5- to 50-fold dilution). Twenty $\mu \mathrm{L}$ of the diluted sample was then directly introduced in the graphite furnace atomic absorption spectrometry (AA6300, Shimadzu, Kyoto, Japan). Two replicate measurements were carried out for each determination. The limit of quantitation, limit of detection, and the linear range for $\mathrm{Mn}$ analysis were $0.5 \mathrm{ng} / \mathrm{ml}, 0.1 \mathrm{ng} / \mathrm{ml}$, and $0.5-35 \mathrm{ng} / \mathrm{ml}$, respectively. The intra- and interday precision of the assay expressed as a coefficient of variation (CV\%) ranged from $3.0 \%$ to $6.8 \%$.

At each visit, thorough physical examination was performed with special focus on motor as well as neurologic development. In addition, both patients underwent rating using the semiquantitative Nijmegen Paediatric Rating Scale ${ }^{11}$ two times, i.e., before initiation of manganese substitution and after 476 and 414 days of therapy, respectively. Subject A had a brain magnetic resonance image (MRI) on three occasions, once before manganese substitution and at days 259 and 476 of therapy.

\section{Subject A}

\section{RESULTS}

\section{Effects of manganese therapy on glycosylation}

Increasing doses of manganese sulfate led to preserved physiological glycosylation of serum transferrin despite tapering and ultimately cessation of galactose substitution in subject A (Figure 1). Generally, a reduction of the daily galactose dose resulted in an increase of hypogalactosylated trisialo-transferrin above its upper reference value of 6.5 area $\%$. Other transferrin isoforms remained within their respective reference ranges for most of the time. Once an increase in trisialo-transferrin was observed, the daily $\mathrm{MnSO}_{4} \cdot \mathrm{H}_{2} \mathrm{O}$ dose was increased. After discontinuation of oral galactose supplementation, $200 \mathrm{mg}$ of $\mathrm{MnSO}_{4} \cdot \mathrm{H}_{2} \mathrm{O}$ per day, which equals $65 \mathrm{mg}$ manganese, was needed to maintain physiological levels of transferrin glycosylation (Figure 1). Detailed high-performance liquid chromatography measurements of 

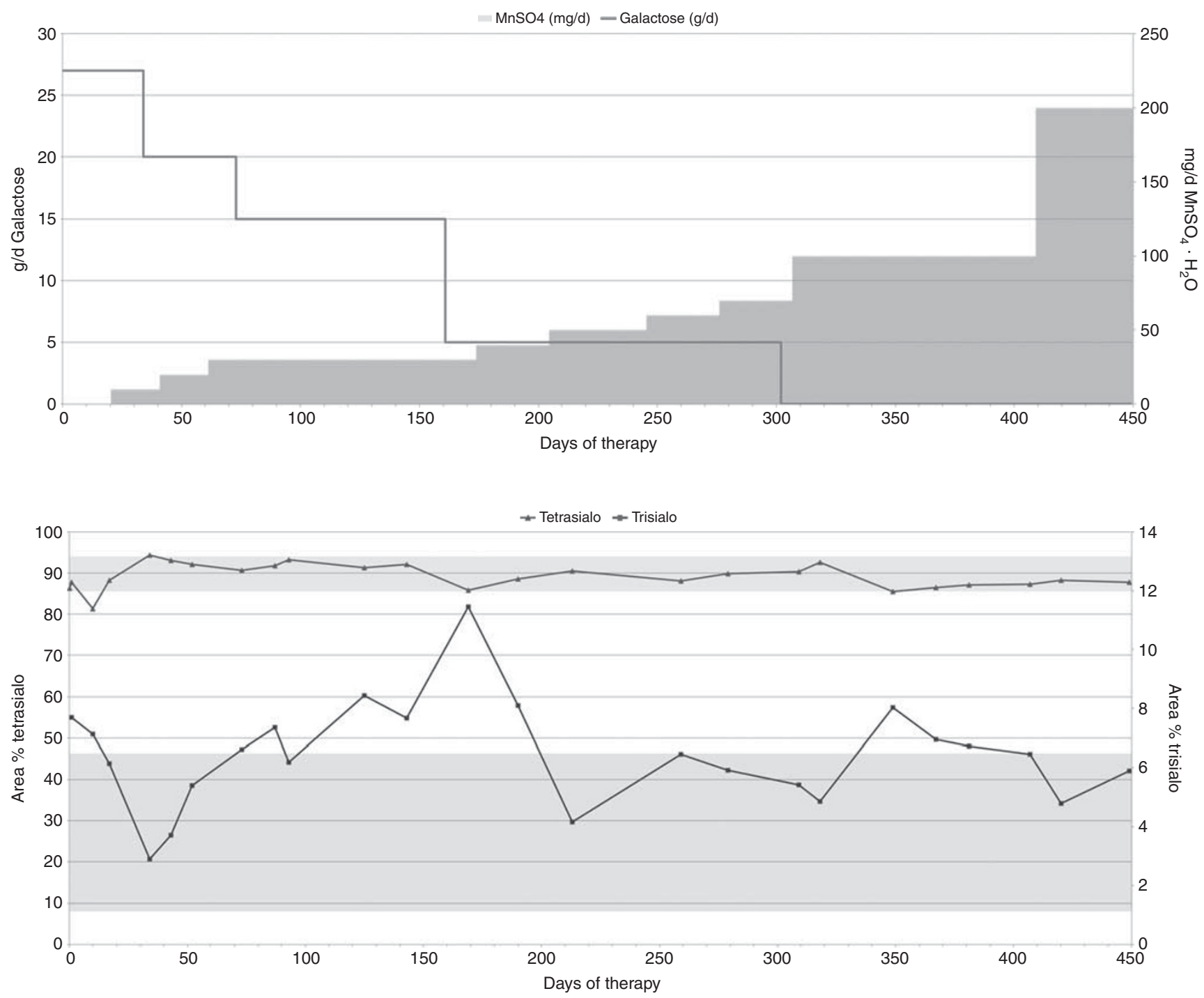

Figure 1 Therapy protocol of subject A. Oral galactose supplementation was tapered and ultimately discontinued while increasing doses of $\mathrm{MnSO}_{4}$. $\mathrm{H}_{2} \mathrm{O}$ were administered orally. The final dose was $200 \mathrm{mg} \mathrm{MnSO}{ }_{4} \cdot \mathrm{H}_{2} \mathrm{O}$ per day, given in five portions in an aqueous solution. This corresponds to $65 \mathrm{mg}$ manganese. Glycosylation improved during manganese substitution. While tetrasialo-transferrin remained within reference ranges for most of the duration of manganese substitution, trisialo-transferrin increased rapidly under insufficient doses of $\mathrm{MnSO}_{4} \cdot \mathrm{H}_{2} \mathrm{O}$. Doses were adapted in response to increases in trisialo-transferrin. A full color version of this figure is available at the Genetics in Medicine journal online.

transferrin glycosylation over the course of the treatment can be found in the Supplementary Materials online.

\section{Blood, urine, and CSF levels of manganese during manganese supplementation}

No manganese was detectable in blood or in urine samples of subject A prior to oral supplementation. ${ }^{1}$ Physiological blood levels of manganese were observed intermittently at different doses of $\mathrm{MnSO}_{4} \cdot \mathrm{H}_{2} \mathrm{O}$, while only a dose of $200 \mathrm{mg} / \mathrm{d}$ resulted in stable physiological levels of blood manganese ranging from 7 to $7.9 \mathrm{ng} / \mathrm{ml}$ (normal range: $7-11 \mathrm{ng} / \mathrm{ml}$ ) (Figure 2).

Urinary manganese levels showed great fluctuation and values both below and above reference ranges $(0.2-1 \mathrm{ng} / \mathrm{ml})$ with the majority surpassing the physiological limit. The values varied considerably even at the same doses of $\mathrm{MnSO}_{4} \cdot \mathrm{H}_{2} \mathrm{O}$.

The manganese level in the subject's CSF at day 476 of therapy with a daily dose of $200 \mathrm{mg}$ of $\mathrm{MnSO}_{4} \cdot \mathrm{H}_{2} \mathrm{O}$ was $1.8 \mu \mathrm{g} / \mathrm{L}$. Since no reference values of manganese in CSF of healthy children are known, we analyzed seven age-matched controls. The mean manganese concentration was $1.84 \mu \mathrm{g} / \mathrm{L}$ $(\mathrm{SD} \pm 0.66)$. This concentration was comparable to that observed in a study by Franěk et al., who measured manganese in CSF of seriously ill children. ${ }^{12}$

\section{Effects of manganese therapy on other manganese-dependent enzymes}

Elevated hypoxanthine levels in subject A decreased to normal levels after 31 days of $\mathrm{MnSO}_{4} \cdot \mathrm{H}_{2} \mathrm{O}$ supplementation and 


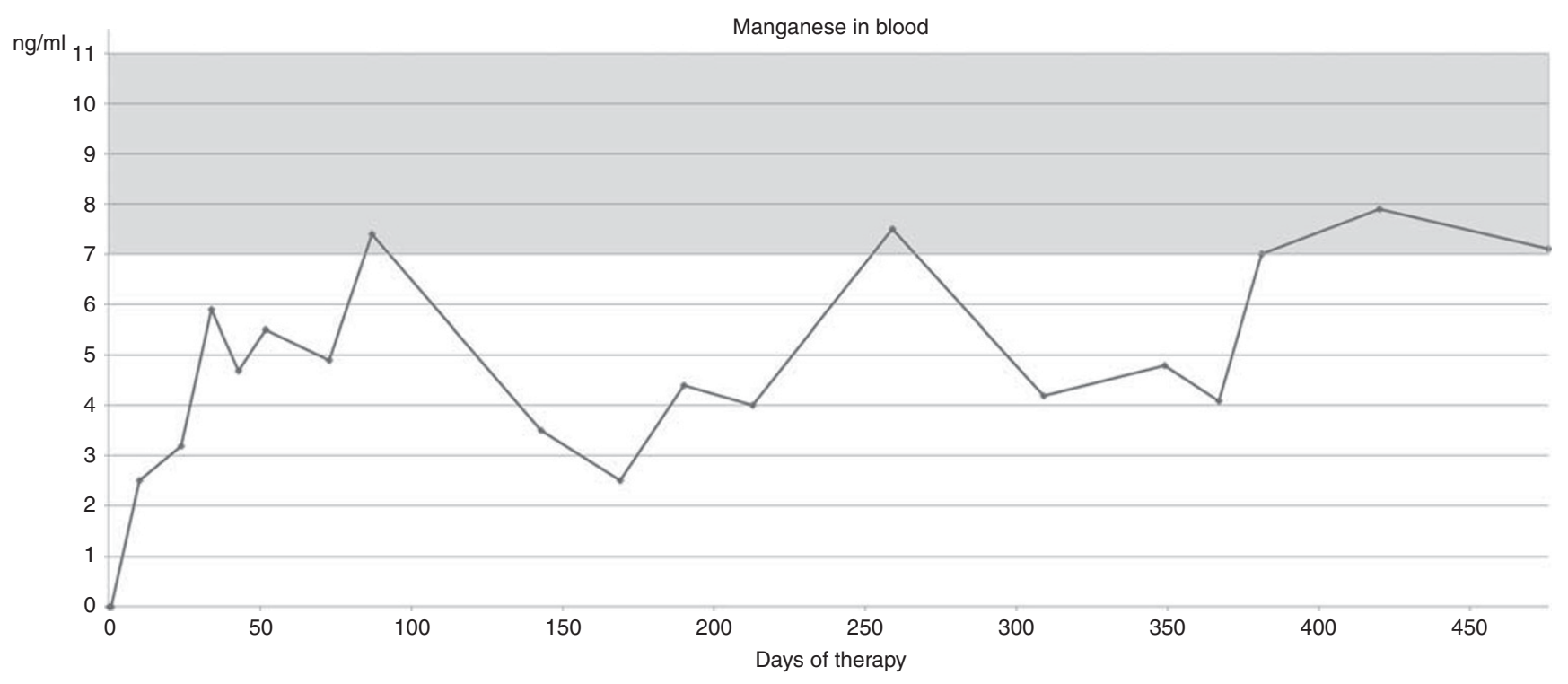

Figure 2 Blood manganese levels of subject A. Blood levels of manganese during supplementation with reference ranges (7-11 $\mathrm{ng} / \mathrm{ml})$ indicated in green. At a dose of $200 \mathrm{mg} \mathrm{MnSO}_{4} \cdot \mathrm{H}_{2} \mathrm{O} / \mathrm{d}$, stable physiological levels of manganese were reached. Reference ranges for manganese in whole-blood samples were not surpassed at any time. A full color version of this figure is available at the Genetics in Medicine journal online.

remained within reference ranges $[<50 \mathrm{mmol} / \mathrm{mol}$ creatinine] throughout the observed period.

Subject A also initially presented with elevated alkaline phosphatase, a finding that has previously been reported in cases of manganese deficiency. ${ }^{13}$ The highest recorded level of 749 U/l (reference: $124-341 \mathrm{U} / \mathrm{l}$ ) was measured shortly before introduction of manganese supplementation. On the 87th day of manganese substitution, at a daily dose of $30 \mathrm{mg} \mathrm{MnSO}_{4}$. $\mathrm{H}_{2} \mathrm{O}$, alkaline phosphatase levels were within normal ranges and no further elevation was measured. A detailed overview of the effects of manganese therapy on laboratory parameters can be found in Supplementary Table S1.

\section{Effects of manganese therapy on clinical presentation}

The clinical presentation improved drastically under $\mathrm{MnSO}_{4}$. $\mathrm{H}_{2} \mathrm{O}$ therapy. The initially observed juvenile seizures with hypsarrhythmia decreased in frequency and in severity. In a control electroencephalogram at day 206 of $\mathrm{MnSO}_{4} \cdot \mathrm{H}_{2} \mathrm{O}$ therapy, no susceptibility to seizures was detectable (Figure 3). The subject has now been clinically seizure-free for over a year. This allowed the reduction of anticonvulsive therapy to $2 \times 300 \mathrm{mg}$ of levetiracetam per day and $125 \mathrm{mg}$ vigabatrin per day without any negative effects.

The improved vision is indicated by the subject's ability to fixate objects as well as persons. She smiles responsively and spontaneously, and shows head control. Her swallowing has improved so that complete oral feeding is now possible.

The subject's hearing improved over the course of manganese supplementation. Initial brain stem electric response audiometry before initiation of manganese substitution revealed severely impaired hearing of the right ear, as well as moderately impaired hearing of the left ear as previously stated. ${ }^{1}$ At a frequency of $500 \mathrm{~Hz}$, the auditory threshold of her left ear was $85 \mathrm{~dB}$ while that of her right ear was above $95 \mathrm{~dB}$. A second examination performed at the time of the second MRI (day 259 of manganese therapy) showed an improvement of hearing of the right ear, especially at high frequencies of $4,000 \mathrm{~Hz}$ with an auditory threshold of $35 \mathrm{~dB}$. The third examination at day 476 of manganese therapy revealed a click threshold of $25 \mathrm{~dB}$ of the right ear and $65 \mathrm{~dB}$ of the left ear. These findings exclude any relevant hearing impairment, indicating remarkable hearing improvement. Motor development was generally favorable although psychomotor disability is still present. The previously existing frequent hyperextension has reduced and the subject is able to grip toys. She shows improved head control, brings her hands to her mouth, and props on her forearms in prone position. These changes were reflected by improvement of the subject's Nijmegen Paediatric Rating Scale scores. The initial score of 40 corresponds to a severe burden of disease. After 476 days of manganese therapy, her score improved to 18 or "moderate."

\section{Neuroradiological findings}

Brain MRI examinations were performed during $\mathrm{MnSO}_{4}$. $\mathrm{H}_{2} \mathrm{O}$ therapy to detect possible manganese accumulation in the brain, especially the basal ganglia as observed in occupational manganism ${ }^{14,15}$ and individuals with disrupted function of SLC30A10. ${ }^{16}$ There were no signs of T1 hyperintensive accumulation of manganese in any of the performed MRI examinations and the subject did not show any symptoms of hypermanganism (Figure 4). The second of the follow-up MRI examinations revealed T2 hyperintensive and $\mathrm{T} 1$ hypointensive bilateral lesions with volume reduction in 


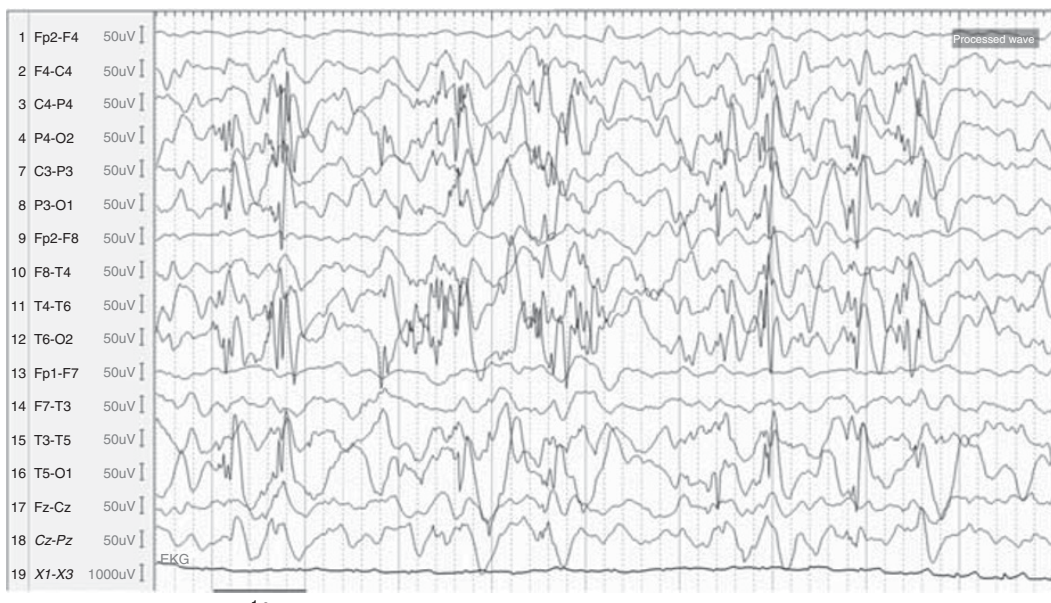

(1)

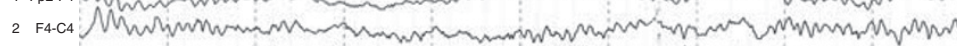
3 C4.P4 UTh 4 P4.02 Wnminn 5 FP1-F3 3 (1) 6 F3.C3 Nminnm 7 СзРз 8 P3.01 Am nom 9 FP2-F8 11 T4-T6 a r m n mom 12 T6-02 Hom 13 FP1-F7 12 (1) 14 F7-T3 - 19 15 T3-T5 w 16 T5.01 $\mathrm{M}$
$\mathrm{M}$

b

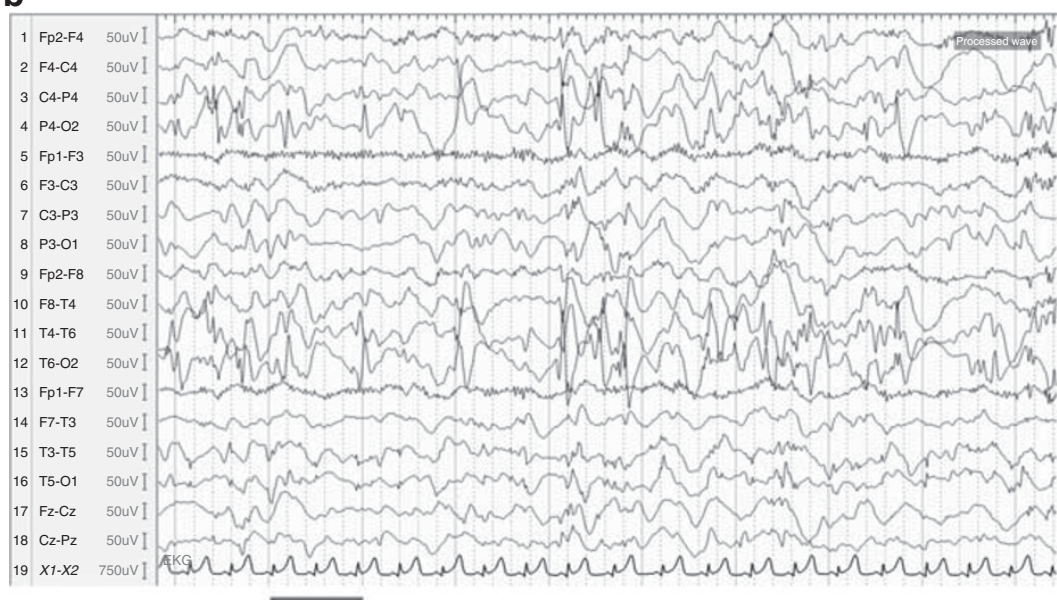

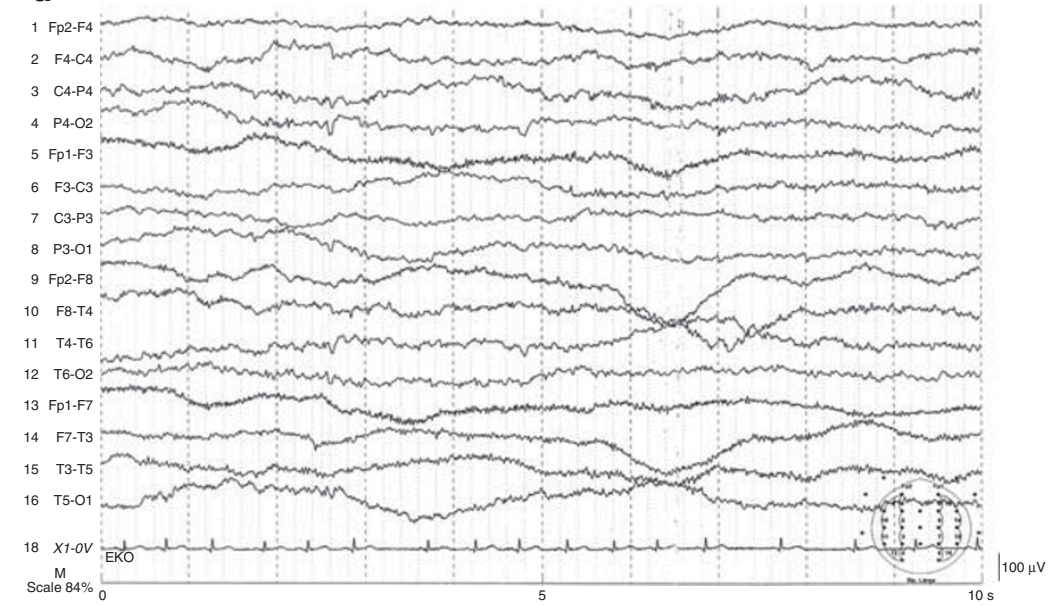

Figure 3 Electroencephalography of subject A during manganese supplementation. (a) At the initial presentation, the subject suffered from severe infantile seizures with hypsarrhythmia. (b) Intensive anticonvulsive therapy with prednisolone, vigabatrin, and phenobarbital was not able to control the seizures. Correspondingly, electroencephalogram revealed prominent right hemispheric spike wave complexes indicating strong susceptibility to seizures. (c) At day 206 of manganese therapy, electroencephalogram recording when sleeping showed no susceptibility to seizures as well as predominant alpha activity at $8 \mathrm{~Hz}$. (d) Electroencephalogram recording when awake at day 318 showed isolated sharp waves over the temporo-occipital region. A full color version of this figure is available at the Genetics in Medicine journal online. 

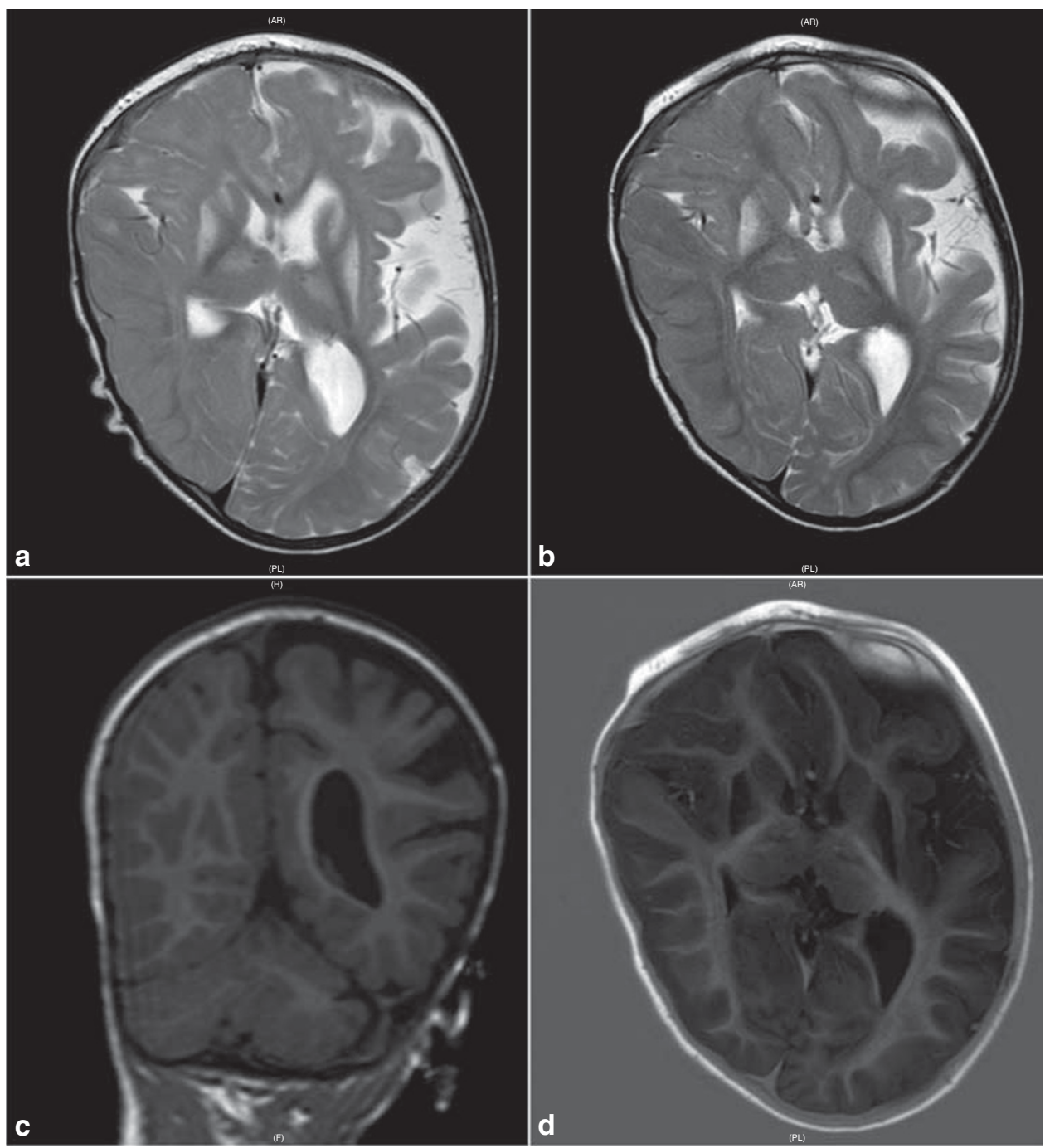

Figure 4 Neuroradiological findings of subject A during $\mathrm{MnSO}_{4} \cdot \mathrm{H}_{2} \mathrm{O}$ substitution. (a) A magnetic resonance image (MRI) examination at day 259 of manganese therapy revealed T2 hyperintensive lesions in the subject's caudate nuclei and putamina, a finding corresponding to those reported by Riley et al. ${ }^{17}$ in two sisters suffering from SLC39A8 deficiency. (b) No progression of the lesions was detected over the course of manganese therapy as demonstrated by an MRI performed at day 476 of therapy. (c,d) No signs of cerebral manganese accumulation were detected in T1 weighted sequences of the MRI performed at day 476. Cranial as well as cerebral asymmetry remains a key feature of the subject's phenotype.

the basal ganglia, especially the caudate nucleus and putamen of the subject. This corresponds to the findings described by Riley et al. ${ }^{17}$ in two sisters suffering from SLC39A8 deficiency presenting with a phenotype characterized by glycosylation abnormalities and Leigh-like syndrome. Blood manganese levels at the time were within the reference ranges $(7.5 \mathrm{ng} / \mathrm{ml})$ and there were no clinical signs of manganism such as psychiatric symptoms, dyskinesia, or tremor. The third MRI showed no progression of these lesions under continued manganese substitution with higher doses of up to $200 \mathrm{mg}$ $\mathrm{MnSO}_{4}$. We therefore do not attribute the observed changes to manganese overload but see them as a sign of neuronal damage due to manganese deficiency.

While cranial synostoses are still present, they did not require surgical treatment to date.

\section{Subject B}

Blood and urine levels of manganese during manganese supplementation

Initially, no manganese was detectable in this subject's blood or urine samples. ${ }^{1}$ During the course of the treatment, blood manganese levels rose and reached physiological values when $600 \mathrm{mg}$ of $\mathrm{MnSO}_{4} \cdot \mathrm{H}_{2} \mathrm{O}$ (corresponding to approximately $195 \mathrm{mg}$ of manganese or $15 \mathrm{mg} \mathrm{MnSO}_{4} \cdot \mathrm{H}_{2} \mathrm{O} / \mathrm{kg}$ bodyweight) was given every day. The measured levels of manganese in urine varied considerably, the highest measured value of $5 \mathrm{ng} /$ $\mathrm{ml}$ having been measured at a $\mathrm{MnSO}_{4} \cdot \mathrm{H}_{2} \mathrm{O}$ dose of $150 \mathrm{mg} / \mathrm{d}$.

\section{Effects of manganese therapy on glycosylation}

In subject $\mathrm{B}$, increased $\mathrm{MnSO}_{4} \cdot \mathrm{H}_{2} \mathrm{O}$ doses also led to improved glycosylation of serum transferrin. Starting from a 

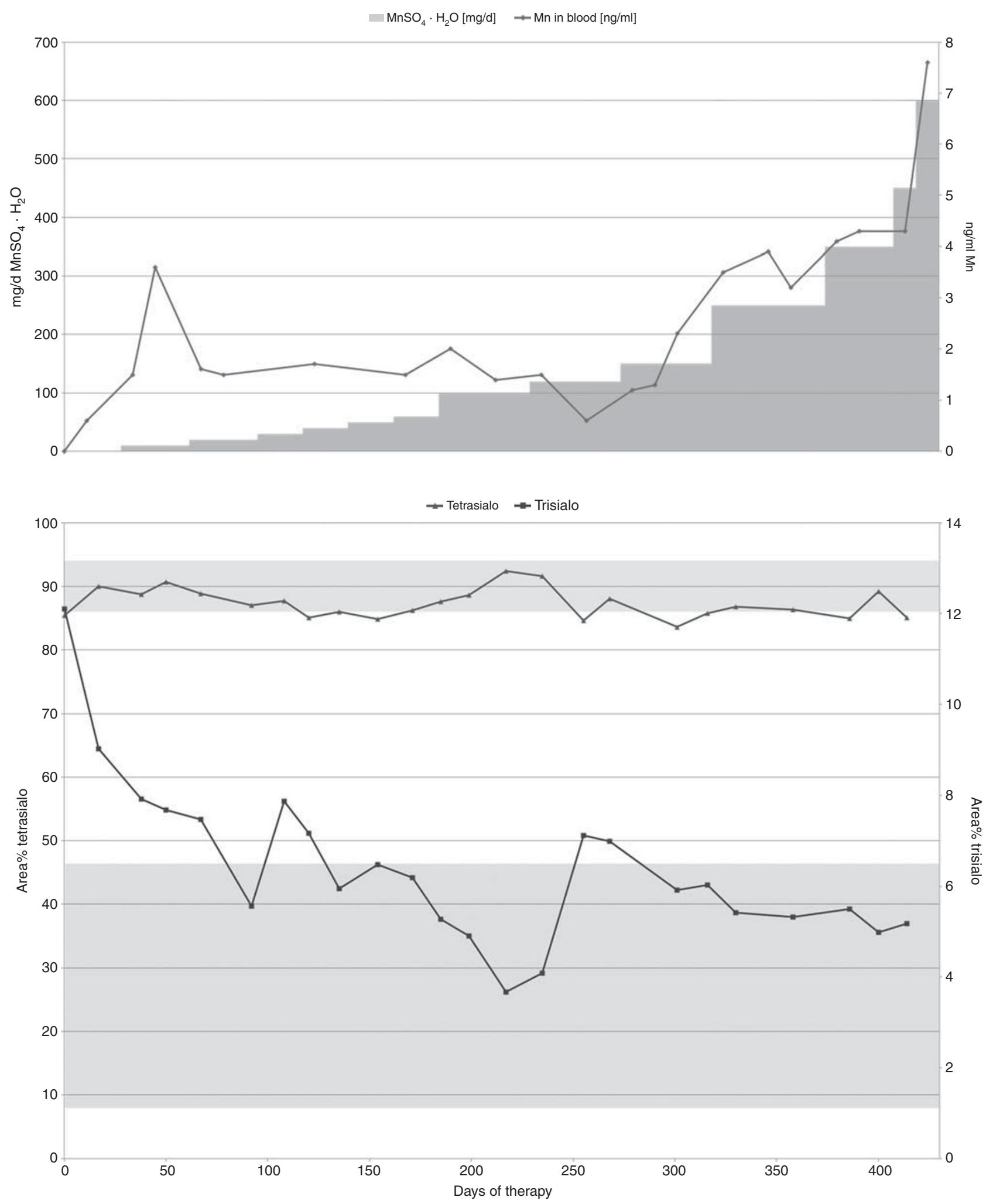

Figure 5 Blood manganese levels and glycosylation changes of subject B during manganese therapy. Subject $\mathrm{B}$ did not receive galactose substitution but was started directly on manganese therapy. Glycosylation improved during $\mathrm{MnSO}_{4} \cdot \mathrm{H}_{2} \mathrm{O}$. The final dose of 600 mg $\mathrm{MnSO}_{4}$. $\mathrm{H}_{2} \mathrm{O}$ resulted in physiological manganese concentrations in whole-blood samples and trisialo-transferrin within normal ranges. A full color version of this figure is available at the Genetics in Medicine journal online. 
lesser degree of hypogalactosylation, her previously elevated trisialo-transferrin fell persistently to values within reference ranges with doses of $150 \mathrm{mg}$ of $\mathrm{MnSO}_{4} \cdot \mathrm{H}_{2} \mathrm{O}$ (corresponding to $49 \mathrm{mg}$ manganese) per day or higher (Figure 5). A detailed overview of the effects of manganese therapy on laboratory parameters can be found in Supplementary Table S2.

\section{Effects of manganese therapy on clinical presentation}

In subject $\mathrm{B}$, improved motor abilities were observed. Previously observed repetitive movements of the head were observed less frequently and she became able to perform the finger-to-nose test indicating reduced ataxia. Muscle strength improved and she is now able to sit without support. The subject's initial Nijmegen Paediatric Rating Scale score was 27, indicating a severe burden of disease. After 414 days of therapy, the score declined to 23 , i.e., moderate affection.

\section{DISCUSSION}

We have demonstrated that oral manganese substitution is a causative treatment for SLC39A8 deficiency. A dose of $200 \mathrm{mg}$ of $\mathrm{MnSO}_{4} \cdot \mathrm{H}_{2} \mathrm{O}$ was able to correct glycosylation and lead to clinical improvement in an individual with a severe form of SLC39A8 deficiency. In a second individual, $600 \mathrm{mg}$ of $\mathrm{MnSO}_{4} \cdot \mathrm{H}_{2} \mathrm{O}$ were needed to maintain physiological $\mathrm{Mn}$ blood levels and to normalize glycosylation. These doses correspond to 20 and $15 \mathrm{mg} / \mathrm{kg}$ bodyweight respectively, indicating the therapeutic range of manganese substitution in SLC39A8 deficiency.

To establish a therapy for the various forms of CDG has been the goal of researchers for a long time. To date, treatment options for several subtypes have been established: MPI-CDG (MIM 602579), which is characterized by severe protein losing enteropathy, can be treated with oral mannose supplementation resulting in loss of symptoms and normalization of glycosylation. ${ }^{18}$ In addition, heparin injections were shown to be an effective symptomatic treatment for protein losing enteropathy in cases where mannose supplementation was not tolerated. ${ }^{19}$

SLC35C1-CDG (MIM 266265), also known as leukocyte adhesion deficiency II, is a disorder affecting leucocyte adhesion, thus resulting in recurring bacterial infections, due to lack of fucosylated selectin ligands. ${ }^{20}$ The patients suffer from severe neurodevelopmental delay. ${ }^{21}$ Oral fucose supplementation results in correctly glycosylated selectin ligands as well as substantial clinical improvement in patients with some mutations. ${ }^{20,22}$

In PGM1-CDG (MIM 614921), a disorder with characteristics of both glycogenosis and CDG, galactose supplementation was shown to improve glycosylation as well as clinical presentation..$^{33,24}$

Galactose substitution is also a treatment option for SLC35A2-CDG. This disorder resembles clinically SLC39A8 deficiency with encephalopathy (epilepsy, severe psychomotor disability, blindness, cerebral atrophy) and dysmorphism. ${ }^{8,9}$ Galactose therapy leads to near-complete normalization of transferrin glycosylation and clinical improvement. ${ }^{9}$
SLC39A8 deficiency differs from the aforementioned CDG subtypes since it is primarily a disorder of manganese metabolism that results in secondary hypoglycosylation and the first glycosylation disorder caused by abnormalities in trace element metabolism. While galactose supplementation was effective in restoring glycosylation, it did not affect other aspects of the disorder caused by lack of manganese in a variety of manganese-dependent enzymes. Manganese supplementation represents a better therapeutic approach than galactose therapy since it is able to correct all biochemical abnormalities that have been detected so far. In this study, we aimed to establish whether manganese replacement is able to lead to a biochemical correction as well as clinical improvement. Moreover, we aimed to find the appropriate dose of $\mathrm{MnSO}_{4} \cdot \mathrm{H}_{2} \mathrm{O}$ as well as to identify possible biomarkers for therapy control.

$\mathrm{MnSO}_{4} \cdot \mathrm{H}_{2} \mathrm{O}$ supplementation was indeed able to correct defective glycosylation in SLC39A8 deficiency without additional galactose supplementation in both subjects. The daily dose needed for complete and persistent correction of glycosylation was $200 \mathrm{mg}$ at a bodyweight of $9.24 \mathrm{~kg}$, corresponding to approximately $21.6 \mathrm{mg} / \mathrm{kg}$ bodyweight and $600 \mathrm{mg}$ at a bodyweight of $40 \mathrm{~kg}(15 \mathrm{mg} / \mathrm{kg}$ bodyweight $)$ respectively. At these doses, blood concentrations of manganese stabilized at physiological levels in both subjects.

Subject A's manganese levels in CSF were comparable to those measured in healthy age-matched controls. This indicates that the administered quantity of $\mathrm{MnSO}_{4} \cdot \mathrm{H}_{2} \mathrm{O}$ is sufficient to assure physiological manganese levels in the CSF. The mechanism by which manganese crosses the blood-brain or rather blood-CSF barrier ${ }^{25}$ remains unclear. Recent data shows the involvement of a variety of transport mechanisms with transferrin-mediated $\mathrm{Mn}$-influx possibly being the major uptake route. ${ }^{26,27}$ There is evidence indicating a carrier-switch from transferrin-mediated to citrate-mediated influx of $\mathrm{Mn}$ in cases of chronic manganese exposure. ${ }^{28}$ While SLC39A8 seems to play no role in $\mathrm{Mn}$ transport across the blood-brain or blood-CSF barrier, it is known to facilitate neuronal Mn uptake. $^{29}$

The normalization of biochemical parameters was accompanied by a remarkable clinical improvement as reflected by the ameliorated Nijmegen Paediatric Rating Scale scores. It has to be noted, however, that the scale is not validated for patients older than 18 years and that subject B was 19 years old when manganese substitution began. The scores for this patient do however give an indication of the clinical improvement observed.

In both subjects, the most sensitive parameter for sufficient manganese uptake seemed to be (dys-)glycosylation, which was used as an indicator to establish the necessary amount of daily $\mathrm{MnSO}_{4} \cdot \mathrm{H}_{2} \mathrm{O}$ intake. Other diagnostic parameters such as elevated urinary hypoxanthine excretion and elevated alkaline phosphatase in subject A normalized rapidly at low doses of manganese sulfate, when glycosylation was still insufficient. The search for better biomarkers to monitor manganese uptake remains an important goal of future research. 
Recently, alterations in manganese homeostasis of the Golgi have emerged as a key pathogenetic feature of hypoglycosylation in TMEM165-deficiency (MIM 614727). This CDG-subtype is characterized by a severe phenotype consisting of dwarfism, psychomotor retardation, liver disease, skeletal malformations, and other dysmorphic features. ${ }^{30-32}$ Interestingly, the examined N-glycans of these patients are hypogalactosylated, a feature shared with SLC39A8 deficiency. ${ }^{31}$ In a study performed on TMEM165depleted cells, manganese substitution in the form of both $\mathrm{MnCl}_{2}$ and $\mathrm{MnSO}_{4}$ corrected hypoglycosylation in both HeLa and HEK293 cells. ${ }^{33}$ These findings are suggestive of another application of $\mathrm{MnSO}_{4} \cdot \mathrm{H}_{2} \mathrm{O}$ substitution in the future and require further investigation.

The main obstacle toward successful manganese substitution therapy in these disorders is the possible toxic effect of manganese. It is well established that chronic exposure to manganese, e.g., in industrial workers or welders, leads to manganism, a disorder characterized by Parkinsonism as well as psychiatric symptoms. ${ }^{5}$ Cranial MRI usually reveals bilateral T1 hyperintense lesions in the globus pallidus while T2 weighted images are unremarkable in these cases. ${ }^{14}$ In addition to this environmental exposure, there are also inborn errors of metabolism leading to toxic amounts of manganese circulating in the body: mutations in SLC39A14 (MIM 608736) were recently shown to disrupt manganese metabolism, leading to manganese accumulation and an early-onset dystonic phenotype resembling the manganism found in cases of chronic manganese exposure. ${ }^{16}$ Variants in SLC30A10 (MIM 611146) coding for another manganese transporter protein cause similarly elevated levels of manganese. ${ }^{34}$ While individuals affected by this disorder also show neurologic symptoms as well as the somewhat pathognomonic T1 hyperintense lesions in brain MRI, liver disease, especially cirrhosis, is a hallmark of this particular disturbance in manganese metabolism. ${ }^{34,35}$

During manganese supplementation, we did not observe any symptoms of manganese toxicity in either subject and two cranial MRI examinations of subject A during the observed period of therapy did not reveal any changes suspicious of manganese overexposure. In addition, manganese levels in whole-blood samples were analyzed regularly and remained within the lower normal reference range (reference: $7-11 \mathrm{ng} / \mathrm{ml}$ ). However, manganese in wholeblood samples is an imperfect biomarker at best since a reliable marker for continuous manganese uptake has not been established., ${ }^{3,5}$ Urinary manganese levels were even less consistent and ranged mostly above reference levels, although manganese excretion via urine is physiologically low. ${ }^{36}$ This can in part be explained by the fact that ZIP8 is primarily expressed in the proximal tubule (S3 segment) of the kidney $y^{37,38}$ and is believed to play a major role in tubular manganese reuptake. ${ }^{38}$ Our findings support this notion since we observed elevated manganese excretion at physiological blood levels in patients with SLC39A8 deficiency.
In summary, manganese supplementation in SLC39A8 deficiency corrects all biochemical abnormalities and leads to major clinical improvement. Compared to the normal daily intake of 1-2 mg manganese in adults, the required therapeutic dose is much higher. Manganese therapy should be monitored closely to prevent manganism. Individual dose finding is needed to ensure optimal treatment. We suggest regular evaluation using transferrin glycosylation as the main marker for sufficient manganese substitution in these patients. The administered manganese doses should be sufficient to restore glycosylation. In addition, manganese blood levels should be monitored. We did not observe any transgression of upper reference values during therapy. Furthermore, frequent neurologic examination as well as regular brain MRIs should be performed to detect signs of manganism such as psychiatric abnormalities, dystonia, and manganese deposition in the basal ganglia. While we did not observe any adverse effects or signs of manganese toxicity, the observational period of more than one year might in fact be too short to identify some adverse effects. Therefore, patients should be followed up closely during the entire time of therapy and preferably even after possible discontinuation.

Further research regarding biomarkers of long-term manganese exposition is needed to facilitate therapy control.

\section{SUPPLEMENTARY MATERIAL}

Supplementary material is linked to the online version of the paper at http://www.nature.com/gim

\section{ACKNOWLEDGMENTS}

We are grateful to both girls and their families for their continuous support during the conception of the study.

\section{DISCLOSURE}

The authors declare no conflict of interest.

\section{REFERENCES}

1. Park JH, Hogrebe M, Gruneberg M, et al. SLC39A8 deficiency: a disorder of manganese transport and glycosylation. Am J Hum Genet. 2015;97: 894-903.

2. Boycott $\mathrm{KM}$, Beaulieu $\mathrm{CL}$, Kernohan KD, et al. Autosomal-recessive intellectual disability with cerebellar atrophy syndrome caused by mutation of the manganese and zinc transporter gene SLC39A8. Am J Hum Genet. 2015:97:886-893.

3. Chen P, Chakraborty S, Mukhopadhyay S, et al. Manganese homeostasis in the nervous system. J Neurochem. 2015;134:601-610.

4. Leach RM, Lilburn MS. Manganese metabolism and its function. World Rev Nutr Diet. 1978;32:123-134.

5. Avila DS, Puntel RL, Aschner M. Manganese in health and disease. Met lons Life Sci. 2013;13:199-227.

6. Powell JT, Brew K. Metal ion activation of galactosyltransferase. J Biol Chem. 1976;251:3645-3652.

7. Kuhn NJ, Ward S, Leong WS. Submicromolar manganese dependence of Golgi vesicular galactosyltransferase (lactose synthetase). Eur J Biochem. 1991:195:243-250.

8. Ng BG, Buckingham KJ, Raymond K, et al. Mosaicism of the UDPgalactose transporter SLC35A2 causes a congenital disorder of glycosylation. Am J Hum Genet. 2013;92:632-636.

9. Dorre $K$, Olczak $M$, Wada $Y$, et al. A new case of UDP-galactose transporter deficiency (SLC35A2-CDG): molecular basis, clinical phenotype, and therapeutic approach. J Inherit Metab Dis. 2015;38:931-940.

10. Ross AC. Modern Nutrition in Health and Disease. Wolters Kluwer Health: Philadelphia, PA, 2014. 
11. Achouitar S, Mohamed M, Gardeitchik T, et al. Nijmegen paediatric CDG rating scale: a novel tool to assess disease progression. J Inherit Metab Dis. 2011:34:923-927.

12. Franěk $T, K o t a s ̌ k a ~ K$, Průša R. Manganese and selenium concentrations in cerebrospinal fluid of seriously ill children. J Clin Lab Anal; e-pub ahead of print 15 February 2017.

13. Friedman BJ, Freeland-Graves JH, Bales CW, et al. Manganese balance and clinical observations in young men fed a manganese-deficient diet. 1987:117:133-143.

14. Nelson K, Golnick J, Korn T, Angle C. Manganese encephalopathy: utility of early magnetic resonance imaging. $\mathrm{Br} J$ Ind Med. 1993;50: 510-513.

15. Crossgrove J, Zheng W. Manganese toxicity upon overexposure. NMR Biomed. 2004;17:544-553.

16. Tuschl K, Meyer E, Valdivia LE, et al. Mutations in SLC39A14 disrupt manganese homeostasis and cause childhood-onset parkinsonismdystonia. Nat Commun. 2016;7:11601.

17. Riley LG, Cowley MJ, Gayevskiy V, et al. A SLC39A8 variant causes manganese deficiency, and glycosylation and mitochondrial disorders. J Inherit Metab Dis. 2017;40:261-269.

18. Niehues R, Hasilik M, Alton G, et al. Carbohydrate-deficient glycoprotein syndrome type $\mathrm{lb}$. Phosphomannose isomerase deficiency and mannose therapy. J Clin Invest. 1998;101:1414-1420.

19. Liem YS, Bode L, Freeze HH, Leebeek FW, Zandbergen AA, Paul Wilson J. Using heparin therapy to reverse protein-losing enteropathy in a patient with CDG-Ib. Nat Clin Pract Gastroenterol Hepatol. 2008;5: 220-224.

20. Marquardt T, Luhn K, Srikrishna G, Freeze HH, Harms E, Vestweber D. Correction of leukocyte adhesion deficiency type II with oral fucose. Blood. 1999;94:3976-3985.

21. Etzioni A, Frydman M, Pollack S, et al. Brief report: recurrent severe infections caused by a novel leukocyte adhesion deficiency. N Eng/ J Med. 1992;327:1789-1792.

22. Wild MK, Luhn K, Marquardt T, Vestweber D. Leukocyte adhesion deficiency II: therapy and genetic defect. Cells Tissues Organs. 2002;172: 161-173.

23. Tegtmeyer LC, Rust $S$, van Scherpenzeel M, et al. Multiple phenotypes in phosphoglucomutase 1 deficiency. N Engl J Med. 2014;370: 533-542.

24. Schrapers E, Tegtmeyer LC, Simic-Schleicher G, et al. News on clinical details and treatment in PGM1-CDG. JIMD Rep. 2016;26:77-84.
25. Bornhorst J, Wehe CA, Huwel S, Karst U, Galla HJ, Schwerdtle T. Impact of manganese on and transfer across blood-brain and bloodcerebrospinal fluid barrier in vitro. J Biol Chem. 2012;287:17140-17151.

26. Aschner M, Aschner JL. Manganese transport across the blood-brain barrier: relationship to iron homeostasis. Brain Res Bull. 1990;24: 857-860.

27. Crossgrove JS, Allen DD, Bukaveckas BL, Rhineheimer SS, Yokel RA. Manganese distribution across the blood-brain barrier. I. Evidence for carrier-mediated influx of managanese citrate as well as manganese and manganese transferrin. Neurotoxicology. 2003;24:3-13.

28. Michalke B, Aslanoglou L, Ochsenkuhn-Petropoulou M, et al. An approach for manganese biomonitoring using a manganese carrier switch in serum from transferrin to citrate at slightly elevated manganese concentration. J Trace Elem Med Biol. 2015;32:145-154.

29. Horning KJ, Caito SW, Tipps KG, Bowman AB, Aschner M. Manganese is essential for neuronal health. Annu Rev Nutr. 2015;35:71-108.

30. Zeevaert R, de Zegher F, Sturiale L, et al. Bone dysplasia as a key feature in three patients with a novel congenital disorder of glycosylation (CDG) type II due to a deep intronic splice mutation in TMEM165. JIMD Rep. 2013;8:145-152.

31. Foulquier $\mathrm{F}$, Amyere M, Jaeken J, et al. TMEM165 deficiency causes a congenital disorder of glycosylation. Am J Hum Genet. 2012;91: $15-26$.

32. Schulte Althoff S, Gruneberg M, Reunert J, et al. TMEM165 deficiency: postnatal changes in glycosylation. JIMD Rep. 2016;26:21-29.

33. Potelle $S$, Morelle W, Dulary E, et al. Glycosylation abnormalities in Gdt1p/TMEM165 deficient cells result from a defect in Golgi manganese homeostasis. Hum Mol Genet. 2016;25:1489-1500.

34. Tuschl K, Clayton PT, Gospe SM Jr., , et al. Syndrome of hepatic cirrhosis, dystonia, polycythemia, and hypermanganesemia caused by mutations in SLC30A10, a manganese transporter in man. Am J Hum Genet. 2012;90: 457-466.

35. Klos KJ, Ahlskog JE, Kumar N, et al. Brain metal concentrations in chronic liver failure patients with pallidal T1 MRI hyperintensity. Neurology. 2006;67:1984-1989.

36. Aschner JL, Aschner M. Nutritional aspects of manganese homeostasis. Mol Aspects Med. 2005;26:353-362.

37. Uhlén M, Fagerberg L, Hallström BM, et al. Proteomics. Tissue-based map of the human proteome. Science. 2015;347:1260419.

38. Fujishiro H, Yano Y, Takada Y, Tanihara M, Himeno S. Roles of ZIP8, ZIP14, and DMT1 in transport of cadmium and manganese in mouse kidney proximal tubule cells. Metallomics. 2012;4:700-708. 